Association for Information Systems AIS Electronic Library (AISeL)

WHICEB 2017 Proceedings

Wuhan International Conference on e-Business

Summer 5-26-2017

\title{
IT Enabled Organizational Agility and Firm Performance: Evidence from Chinese Firms
}

\author{
Yunshi Mao \\ SYS School of Business Sun Yat-sen University, Guangzhou, China E-mail, mnsmys@mail.sysu.edu.cn \\ Jing Quan \\ Franklin P. Perdue School of Business Salisbury University, jxquan@salisbury.edu
}

Follow this and additional works at: http://aisel.aisnet.org/whiceb2017

\section{Recommended Citation}

Mao, Yunshi and Quan, Jing, "IT Enabled Organizational Agility and Firm Performance: Evidence from Chinese Firms" (2017). WHICEB 2017 Proceedings. 59.

http://aisel.aisnet.org/whiceb2017/59

This material is brought to you by the Wuhan International Conference on e-Business at AIS Electronic Library (AISeL). It has been accepted for inclusion in WHICEB 2017 Proceedings by an authorized administrator of AIS Electronic Library (AISeL). For more information, please contact elibrary@aisnet.org. 


\title{
IT Enabled Organizational Agility and Firm Performance:
}

\section{Evidence from Chinese Firms}

\author{
Yunshi Mao ${ }^{1}$, Jing Quan ${ }^{2}$ \\ ${ }^{1}$ SYS School of Business Sun Yat-sen University, Guangzhou, China E-mail: \\ mnsmys@mail.sysu.edu.cn \\ ${ }^{2}$ Franklin P. Perdue School of Business Salisbury University jxquan@ salisbury.edu
}

\begin{abstract}
In this study, we examine the role of information technology (IT) in improving organizational agility and firm performance from the perspectives of the resource-picking and capability-building mechanisms of rent creation, and the hierarchy of dynamic capabilities. We divide IT capabilities into IT exploration capability, which corresponds to the resource-picking phase, and IT exploitation capability, which corresponds to the capability-building phase. Based on the concept of a hierarchy of dynamic capabilities, we establish the theoretical links between lower order capabilities (IT exploitation), higher order capabilities (organizational agility), and performance. Using the partial least squares (PLS) structural equation modeling approach, we empirically test the proposed relationships using data from 289 manufacturers in the Pearl River Delta region of Guangdong, China. Our results suggest that 1) IT exploration capability (resource picking) affects IT exploitation capability (capability building); 2) IT exploitation capability has positive effects on customer, operational, and partner agilities (higher order of capabilities); and 3) the IT enabled organizational agilities positively affect firm performance. We discuss the theoretical and practical implications of our findings and the opportunities for future research.
\end{abstract}

Keywords: agility, capability building, firm performance, IT exploration capability, IT exploitation capability, resource picking

\section{INTRODUCTION}

Agility is one of the key strategies organizations deploy to cope with highly volatile external and internal changes (Dove, 2002; Kassim et al., 2004; Mathiassen et al., 2006; Sambamurthy et al., 2003; Sharifi et al., 2001). Agility refers to a firm's capability to respond to unpredictable changes in the business environment and, more importantly, to exploit and take advantage of these changes. An agile firm is better positioned to sustain competitive advantage during periods of uncertainty and turbulence in the business environment.

Recent research has been showing increasing interest in the enabling role of information technology (IT) in shaping organizational agility. Overby et al. (2006) propose that IT enables both the sensing and responding components of agility by enhancing the reach and richness of a firm's knowledge base and processes. Using survey data from 241 firms, Tallon (2008) finds that technical IT capabilities, together with managerial capabilities, affect agility, and that in a dynamic setting, managerial capabilities are more important than IT capabilities, whereas in a stable setting, IT capabilities are more important. Lee et al. (2008) propose that explorative and exploitative IT capabilities positively affect both entrepreneurial agility and adaptive agility.

Although the existing research has made great progress in enhancing our understanding of IT-enabled agility, a number of areas still need further exploration. First, the dynamic capability perspective and resource-based view cannot fully explain the role IT plays in different stages of deployment. For example, neither perspective can adequately explain why firms must first select the appropriate IT resources before turning them into capabilities. Second, the extant research on the link between agility and performance is largely fragmented. The existing studies (Inman, Sale, Green, \& Whitten, 2011; Ngai, Chau, \& Chan, 2011; Roberts \& Grover, 2012; Yusuf \& Adeleye, 2002) focus on specific types of organizational agility, such as customer, operational, or partner agility. Little research has examined the interrelations between the different types of organizational agility. Third, in terms of context, most of the existing literature focuses on developed countries. While this 
research provides insights on the dynamics of IT-agility relationships, it does not enable us to discern whether the dynamics are different in developing countries. In a recent study, Johns (2006) called for a reexamination of the relationship between context and organizational behavior.

This study extends the current literature on IT enabled business agility in terms of both theory and context. First, we use the resource-picking and capability-building mechanisms of rent creation (Makadok, 2001) and the conceptualization of a hierarchy of capabilities (Grant, 1996) as our theoretical lenses. We attempt to use these lenses to explain the different roles that IT plays in the different stages of IT deployment and the links between IT capabilities and organizational agility. Second, we distinguish between IT exploration capability and IT exploitation capability to further study the conception of IT as an antecedent to organizational agility (Lee et al., 2008; Mithas, Ramasubbu, \& Sambamurthy, 2011; Overby et al., 2006; Tallon, 2008). Explorative IT capability refers to the ability of a firm to acquire new IT resources for future use in the firm. IT exploitation capability refers to the ability of a firm to utilize its IT resources to improve its existing processes or create new ones (Lee et al., 2008). Explorative IT capability corresponds to the resource-picking phase of rent creation illustrated by Makadok (2001), while IT exploitation corresponds to the capability-building phase. Third, we conceptualize the effect of IT on firm performance through its ability to enhance firm agility. In other words, agility acts as a mediator between IT and firm performance. This conceptualization is in line with the argument that organizational agility mediates the effect of information technology on firm performance (Tallon \& Pinsonneault, 2011; Sambamurthy et al., 2003).

Another theoretical contribution of this study is our differentiation between the three distinct types of organizational agility, namely, the customer, operational, and partner agilities (Sambamurthy et al., 2003). These three agilities cover the entire value chain of a firm from suppliers to internal operations to customers. IT can play an important role in enabling organizational agility by building a firm's capabilities to capture signals from its internal and external environments, analyze the raw signals and turn them into actionable information, and respond to the changes in a timely fashion (Seo \& Paz, 2008). Examining agility in these three interrelated areas not only helps us to overcome the fragmentation of the existing literature, but also enables us to provide insights on the dynamics of the IT-agility-performance relationship.

With respect to context, we focus on Chinese manufacturing firms in the Pearl River Delta region of Guangdong. This region is one of most vibrant economic centers in China and provides a different setting in which to examine the dynamics of the IT-agility relationship than the developed countries that are the focus of most of the existing studies. Given the increasingly complex and turbulent business environment in China, research on organizational agility in this context is particularly pertinent and valuable.

\section{LITERATURE REVIEW, THEORY AND HYPOTHESES}

Resource picking and capability building are two important processes through which firms assemble valuable resources and build their essential capabilities (Makadok, 2001). The concepts of resource picking and capability building stem from the resource-based (Barney, 1991) and dynamic-capability views (Teece, Pisano, \& Shuen, 1997) of the firm, respectively. Resource picking refers to the skill of acquiring superior information to outsmart rivals in procuring good resources and avoiding bad alternatives (Maritan \& Peteraf, 2011), rather than simply the mere procurement and possession of resource bundles. Capability building refers to a firm's ability to effectively deploy its existing internal and external resources to create higher-order value (Grant, 1996). In this regard, capability building mechanisms can be considered dynamic capabilities, which Eisenhardt and Martin (2000) define as "processes to integrate, reconfigure, gain and release resources - to match and even create market change" (p. 1107).

The distinction between the two mechanisms is very important. One of the key differences is their timing. Because resource picking signifies a firm's skill in selecting superior resources and avoiding bad alternatives, economic profit is essentially created before the acquisition of a resource. In contrast, capability building can be 
termed the "deployment of resources" (Maritan \& Peteraf, 2011), meaning that a firm's capabilities only generate economic rent after the resources are in the firm's possession. By definition, the two mechanisms affect performance in sequential order. The resource picking mechanism generates economic rent before the actual acquisition of resources, whereas the capability building mechanism only generates rent when the resources are in place. In short, the effect of the resource picking mechanism precedes that of the capability building mechanism (Makadok, 2001).

Information systems (IS) research has leveraged the resource picking and capability building processes of IT as antecedents to superior firm performance (e.g. Pavlou \& El Sawy 2006). One of the challenges for these studies is to operationalize IT capabilities (Bhatt \& Grover, 2005). For example, using a secondary data set, Santhanam and Hartono (2003) find a positive link between IT capability and firm performance without directly measuring IT capabilities. Karimi et al. (2007) focus on IT capability at the functional/operational level and operationalize enterprise resource planning (ERP) capabilities. Bhatt and Grover (2005) classify IT capabilities into value, heterogeneity, and imperfect mobility, and then operationalize IT capabilities with respect to IT infrastructure, IT business experience, relationship infrastructure, and organizational learning.

\subsection{Explorative and Exploitative IT Capabilities}

Our conceptual framework is rooted in the resource picking and capability-building perspectives. We propose that the ability to select IT resources effectively is antecedent to firm performance as measured by organizational agility. In the resource picking phase, we operationalize one construct, explorative IT capability (ITERC) (Lee et al., 2008). IT exploration refers to the ability of a firm to acquire new IT resources, such as new technologies and new IS applications, for future use within the firm. Because new IT products and services emerge at a rapid pace, firms must pay attention to current and emerging technologies, understand their potential value for business operations, and select promising technologies. This is the decision phase of resource picking (Makadok, 2001), which involves making sense of different information technologies, experimenting with promising technologies to learn about their functionalities, and selecting the few technologies that are most likely to influence the firm's current and future operational capabilities (Lee et al., 2008).

In the capability building phase, we also operationalize one construct, exploitative IT capability (ITEIC) (Lee et al., 2008; Peppard \& Ward, 2004). IT exploitation capability refers to a firm's ability to utilize its existing IT resources to improve existing processes or to create new processes. IT exploitation is associated with a firm's ability to manage, leverage, and reuse its portfolio of IT assets for different business activities, and to integrate the technologies into its business processes (Lee et al., 2008).

Based on the timing of the effects of resource picking and capability building (Makadok, 2001), we propose that explorative IT capability affects exploitative IT capability. The integration of lower order capabilities provides the basis for higher order capabilities. Hence, we formulate our first hypothesis as follows:

$\mathrm{H}_{1}$ : Explorative IT capability has a positive effect on firms' exploitative IT capability.

\subsection{Exploitative IT Capability and Organizational Agility}

We adopt the definition of organizational agility provided by Seo and Paz (2008), "as a set of processes that allows an organization to sense changes in the internal and external environment, respond efficiently and effectively in a timely and cost-effective manner, and learn from the experience to improve the competencies of the organization" (p. 136). We operationalize organizational agility along three dimensions: operational agility, customer agility, and partner agility (Sambamurthy et al., 2003). The three types of agility cover the entire value chain of a firm from suppliers to customers.

Information technology capability can play an enabling role for organizational agility by providing the capabilities to perceive the characteristics of incoming signals from the internal and external environments, to 
filter the raw signals into actionable information, and to respond to the information in a timely manner (Seo \& Paz, 2008). Based on Grant's (1996) conceptualization of a hierarchy of capabilities, we treat exploitative IT capability and organizational agility as the lower and higher orders of organizational capability, respectively. Because organizational agility captures the sensing and responding components of dynamic capabilities, it is appropriate to frame agility as dynamic capability (Roberts \& Grover, 2012).

Specifically, we believe that exploitative IT capability will have a positive effect on customer agility. Although there are various definitions of customer agility, we adopt Roberts and Grover's (2012) definition as, "the degree to which a firm is able to sense and respond quickly to customer-based opportunities for innovation and competitive action" (p. 580). We believe that a firm's ability to utilize its IT resources is critical for enhancing its ability to sense and respond to shifting customer preferences. For example, a firm can direct its IT resources to the business analytics of big data to gain market intelligence, detect opportunities for introducing new products, attract new customers, and retain existing customers. This line of discussion leads to our second set of hypotheses:

$\mathrm{H}_{2 \mathrm{a}}$ : Exploitative IT capability has a positive effect on firms' customer agility.

Next, we believe that a positive relationship exists between exploitative IT capability and operational agility. Operational agility refers to a firm's ability to sense and seize opportunities to improve its business operations and to achieve faster and more accurate and cost effective processes (Sambamurthy et al., 2003). In other words, firms with operational agility can quickly redesign their existing processes and create new processes in response to environmental changes. Pavlou and El Sawy (2006) use a similar concept called "process reconfigurability," which refers to the ability of firms to transform and reconfigure their resources and processes to accommodate changes and to reach their objectives. IT capabilities that link business units, implement common transaction processing, expedite business operations, allow users to quickly access and share business data across the firm, and create synergies across business units are essential to operational agility (Bharadwaj, 2000; Lee, Xu, Kuilboer, \& Ashrafi, 2012; Ravichandran \& Lertwongsatien, 2005).

Firms can enhance their operational agility by leveraging the interconnectivity of virtual markets and performing faster and more informed decision-making. Hence, to support operational agility, management can allocate IT resources to modular operations that enable the firm's business processes to be redesigned and reconfigured in a faster and more responsive manner and new processes to be created in response to changes in the business environment. Moreover, firms can develop IT capabilities for designing metrics and analytics that provide integrated processes, advance warnings of performance degradation in the processes, and the visibility of the real-time performance of various processes.

Based on this line of argument, we propose the following hypothesis:

$\mathrm{H}_{2 \mathrm{~b}}$ : Exploitative IT capability has a positive effect on firms' operational agility.

Finally, we believe that exploitative IT capability can directly enhance partner agility. Sambamurthy et al. (2003) define partner agility as the "ability to leverage the assets, knowledge, and competencies of suppliers, distributors, contract manufacturers, and logistics providers through alliances, partnerships, and joint ventures" (p. 245). Partner agility enables firms to quickly identify appropriate partners or modify their existing partnerships when they need access to external assets, competencies, or knowledge. This avoids the need to internalize processes that may not be aligned with the firm's distinctive competencies or may be difficult and costly to manage. Firms with partner agility enjoy an ecosystem of strategic partnerships that enables them to explore opportunities for innovation and competitive action.

Hence, we propose the following hypothesis:

$\mathrm{H}_{2 \mathrm{c}}$ : Exploitative IT capability has a positive effect on firms' partner agility.

\subsection{Organizational Agility and Firm Performance}


Previous studies have positively identified the link between agility and firm performance. Roberts and Grover (2012) find that firm performance is significantly related to customer agility. They propose that the alignment between firms' customer sensing and customer responding capabilities is the key to better performance because they find that firm performance is higher when the values for sensing and responding are both high than when they are both low. Using a data set of 96 large manufacturers in the U.S., Inman, Sale, Green, and Whitten (2011) examine the effect of just-in-time operations and find that operational agility has a direct positive relationship with firms' financial and market performance. Similarly, Yusuf and Adeleye (2002) find a significant correlation between agility and business performance encompassing sales turnover, market share, customer loyalty, performance relative to competitors, and aggregate performance. Based on the resource-based view, Ngai, Chau, and Chan (2011) propose that partner agility is rare, valuable, and imperfectly imitable, and may therefore result in superior long-term performance. Partner agility helps sustain competitive advantage by enabling firms to continually sense market changes in coordination with the different parties and functions along the value chain and to quickly respond to these changes.

Various performance measures are available. In this study, we focus on financial and market performance. We measure financial performance by a firm's return on investment, return on sales, and profitability compared to its competitors. We measure marketing performance by comparing the firm's sales volume, sales growth, and market share to that of its competitors (Inman, Sale, Green, \& Whitten, 2011).

Based on the above discussion, we propose our final three hypotheses:

$\mathrm{H}_{3 \mathrm{a}}$ : IT enabled customer agility has a positive effect on financial and market performance. $\mathrm{H}_{3 \mathrm{~b}}$ : IT enabled operational agility has a positive effect on financial and market performance.

$\mathrm{H}_{3 \mathrm{c}}$ : IT enabled partner agility has a positive effect on financial and market performance.

We illustrate our research model in Figure 1.

\section{METHODOLOGY}

\subsection{Measurement Development}

We developed our measurements following a four-step procedure: (1) operationalization of the research constructs, (2) item development and validity tests, (3) translation from English to Chinese, and (4) pre-test. Table 1 shows the operationalization of the research constructs and the references used to develop the measurement items.

\subsection{Data Collection}

We conducted our survey in the Pearl River Delta region in Guangzhou, China. Our target firms were manufacturing companies in the region. We decided to focus on manufacturers for two reasons. First, the Chinese economy is currently predominately manufacturing based. Second, this enabled us to minimize any potential cofounding effects due to industry variations (Karimi et al., 2007).

We distributed the questionnaires via two different channels, email and regular mail. First, we used a marketing research center in one of the major local universities to email 1120 copies of questionnaires to the manufacturers in their database. After eliminating returns with incomplete or missing values, we identified 134 usable responses, which represents an effective response rate of 12.0 percent. Second, we commissioned the urban economic management department of a local government in an area with a high concentration of Pearl River Delta manufacturing firms to send 300 questionnaires via regular mail. After eliminating returns with incomplete or missing values, we identified 154 usable questionnaires, giving an effective response rate of 51.3 percent. The discrepancy tests (ANOVA and homogeneity of variances) revealed no significant differences between the responses of these two subsamples in terms of the means and variances. Therefore, we combined the two subsamples to form our study sample of 288 , representing a combined effective response rate of 20.3 percent. 


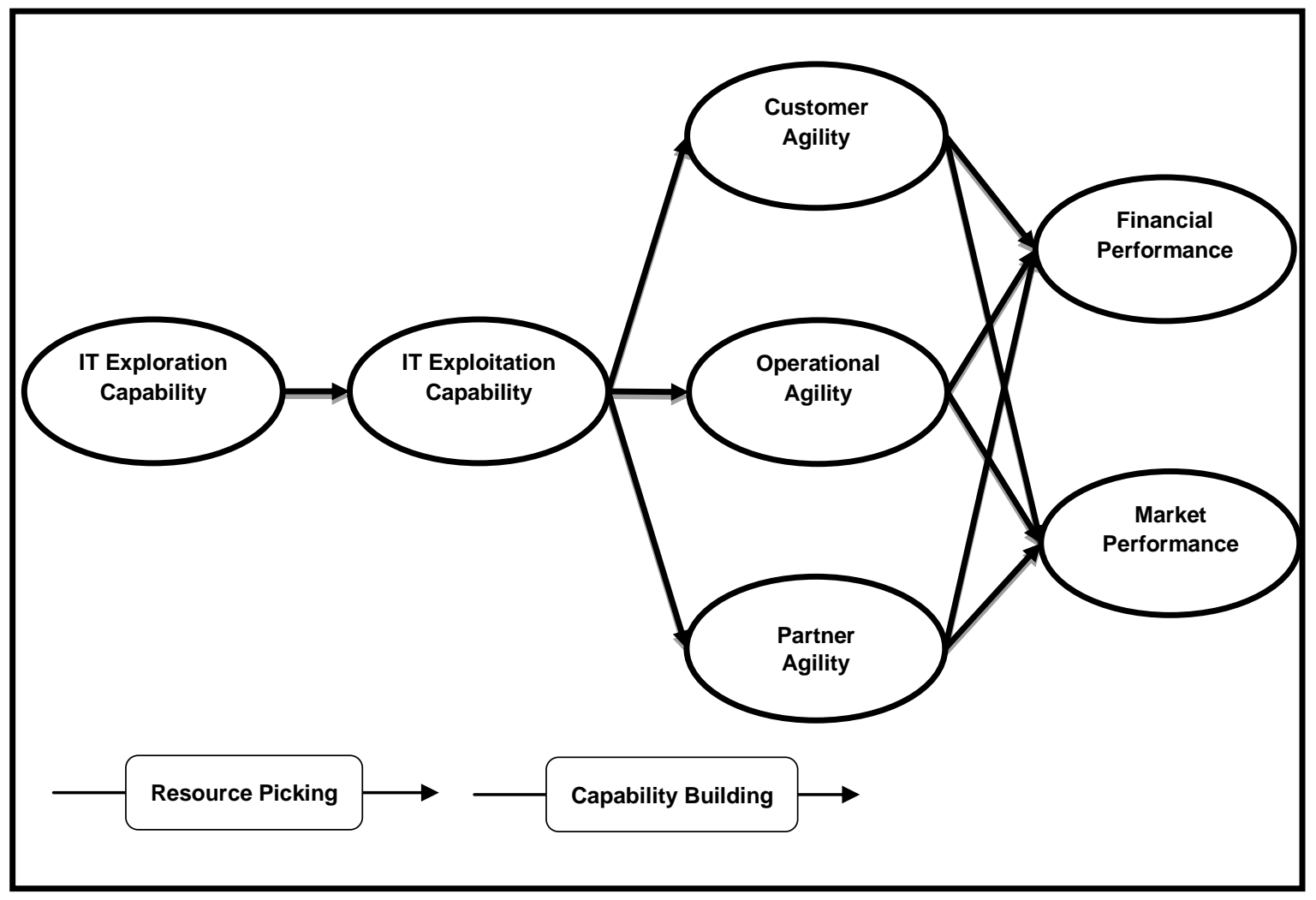

Figure 1. Research Model

Table 1. Measurement References

\begin{tabular}{|l|l|}
\hline Construct & Reference \\
\hline IT Exploration Capability & $\begin{array}{l}\text { Explorative strategic posture (Karimi et al., 2007) and new IT } \\
\text { experimentation (Nambisan, Agarwal, \& Tanniru, 1999). }\end{array}$ \\
\hline IT Exploitation Capability & $\begin{array}{l}\text { Exploitative strategic posture (Atuahene-Gima, 2005) and existing IT } \\
\text { reuse (Ravichandran \& Lertwongsatien, 2005). }\end{array}$ \\
\hline Customer Agility & $\begin{array}{l}\text { The degree to which a firm is able to sense and respond quickly to } \\
\text { customer-based opportunities for innovation and competitive action } \\
\text { (Roberts \& Grover, 2012). }\end{array}$ \\
\hline Operational Agility & $\begin{array}{l}\text { The ability to sense and seize opportunities to improve business } \\
\text { operations and achieve faster and more accurate and cost effective } \\
\text { processes (Sambamurthy et al., 2003). }\end{array}$ \\
\hline Partner Agility & $\begin{array}{l}\text { The ability to leverage the assets, knowledge, and competencies of } \\
\text { suppliers, distributors, contract manufacturers, and logistics providers } \\
\text { through alliances, partnerships, and joint ventures (Sambamurthy et al., } \\
\text { 2003). }\end{array}$ \\
\hline Financial Performance & $\begin{array}{l}\text { A firm's return on investment, return on sales, and profitability as } \\
\text { compared to its competitors (Inman, Sale, Green, \& Whitten, 2011). }\end{array}$ \\
\hline Market Performance & $\begin{array}{l}\text { A firm's sales volume, sales growth, and market share as compared to } \\
\text { its competitors (Inman, Sale, Green, \& Whitten, 2011). }\end{array}$ \\
\hline
\end{tabular}

The company sizes in the final sample varied from five to 500,000 employees. Twenty-seven percent of the companies reported having 100 or fewer employees, 36 percent reported having between 101 and 1000 employees, and 37 percent reported having between 1001 and 500,000 employees. Most of the respondents were senior managers and chairpersons of the board of directors (73 percent of all respondents), while IT managers constituted 17 percent of the respondents. The remaining 10 percent of the respondents fell into the "other" category. 


\section{Data Analysis and Results}

\subsection{Construct Validity of the Measurement Model}

We first used confirmatory factor analysis to check the validity of the indicators for the research constructs. We then used Smart PLS (Ringle, Wende, \& Will, 2005) to solve the structural equation model and test the proposed hypotheses. The factor analysis tested the psychometric properties of the multiple-indicator constructs in our measurement model to establish construct validity by examining (1) the model fit, (2) reliability, and (3) discriminant validity.

As shown in Table 2, all of the item loadings are higher than 0.7 and significant at the 0.01 level. Moreover, the model fit indices of the measurement model suggest an acceptable fit (Purvis et al., 2001). The Chi-square statistic of 538.343 divided by the degrees of freedom of 249 yields 2.162 , indicating a good fit as it is below the recommended threshold of three. The confirmatory factor analysis (CFA) results show that the RMSEA of 0.0586 is below the criteria of 0.06 or less, indicating an acceptable model fit. Furthermore, the CFI (0.972), NFI (0.951), NNI (0.944), and GFI (0.901) all meet the criteria of 0.90 or larger for an acceptable fit.

Second, as shown in Table 2, the internal consistency reliability scores (Cronbach's $\alpha$ ) for all of the constructs are much higher than the recommended 0.5 threshold, indicating evidence of good measurement properties. In addition, the average variance extracted (AVE) scores for all of the constructs are above 0.5, confirming that all of the constructs have satisfactory convergent validity.

Table 2. Measurement Model and Convergent Validity

\begin{tabular}{|c|c|c|c|c|c|}
\hline Construct & Item & Factor Loading & AVE & Composite Reliability & Cronbach's $\alpha$ \\
\hline \multirow{3}{*}{$\begin{array}{l}\text { IT Exploration } \\
\text { Capability (ITERC) }\end{array}$} & ITERC1 & 0.94 & .89 & .96 & .94 \\
\hline & ITERC2 & 0.95 & & & \\
\hline & ITERC3 & 0.93 & & & \\
\hline \multirow{3}{*}{$\begin{array}{l}\text { IT Exploitation } \\
\text { Capability (ITEIC) }\end{array}$} & ITEIC1 & 0.96 & .91 & .97 & .95 \\
\hline & ITEIC2 & 0.96 & & & \\
\hline & ITEIC3 & 0.95 & & & \\
\hline \multirow{3}{*}{$\begin{array}{l}\text { Customer Agility } \\
\text { (CA) }\end{array}$} & CA1 & 0.94 & .86 & .95 & .92 \\
\hline & CA2 & 0.95 & & & \\
\hline & CA3 & 0.89 & & & \\
\hline \multirow{2}{*}{$\begin{array}{l}\text { Operational Agility } \\
\text { (OA) }\end{array}$} & OA1 & 0.96 & .92 & .96 & .92 \\
\hline & OA2 & 0.97 & & & \\
\hline \multirow{3}{*}{ Partner Agility } & PA1 & 0.88 & .87 & .95 & .92 \\
\hline & PA2 & 0.95 & & & \\
\hline & PA3 & 0.96 & & & \\
\hline \multirow{3}{*}{$\begin{array}{l}\text { Financial } \\
\text { Performance }\end{array}$} & FP1 & 0.91 & .92 & .97 & .96 \\
\hline & FP2 & 0.94 & & & \\
\hline & FP3 & 0.98 & & & \\
\hline \multirow{3}{*}{ Market Performance } & MP1 & 0.81 & .83 & .94 & .90 \\
\hline & MP2 & 0.98 & & & \\
\hline & MP3 & 0.78 & & & \\
\hline
\end{tabular}

Finally, the results in Table 3 provide strong evidence of discriminant validity. For each pair of constructs, the square root value of the AVE is greater than the correlation between the constructs. This demonstrates that the constructs satisfy the requirements for discriminant validity.

Overall, our tests establish the construct validity of our measurement model by showing that the measurement items converge on their respective constructs and the constructs are distinct from each other. 
Table 3. Discriminant Validity

\begin{tabular}{|l|l|l|l|l|l|l|l|}
\hline & ITERC & ITEIC & CA & OA & PA & FP & MP \\
\hline ITERC & 0.94 & & & & & & \\
\hline ITEIC & 0.71 & 0.96 & & & & & \\
\hline CA & 0.47 & 0.51 & 0.93 & & & & \\
\hline OA & 0.49 & 0.47 & 0.64 & 0.96 & & & \\
\hline PA & 0.57 & 0.61 & 0.58 & 0.54 & 0.93 & & \\
\hline FP & 0.45 & 0.47 & 0.47 & 0.53 & 0.50 & 0.96 & \\
\hline MP & 0.51 & 0.54 & 0.56 & 0.53 & 0.56 & 0.78 & 0.91 \\
\hline
\end{tabular}

Note: The shaded numbers shown on the diagonal are the square roots of the average variance extracted (AVE).

\subsection{PLS Structural Model Results}

We first ran the PLS algorithm to estimate the path coefficients and $\mathrm{R}^{2} \mathrm{~s}$, and then used bootstrapping with 200 re-samples to obtain the t-statistics for testing the statistical significance of the paths. Our results, shown in Figure 2, reveal that the structural model explained $50 \%, 27 \%, 23 \%, 38 \%, 35 \%$, and $42 \%$ of the variation in IT exploitative capability, customer agility, operational agility, partner agility, financial performance, and market performance, respectively. All of the percentages are above the suggested threshold of $10 \%$, suggesting that our structural model provided adequate explanatory power. In addition, the ideal path coefficients should exceed 0.2 and have significant t-statistics. Our results show that the path coefficients are well above 0.2 and very significant. Specifically, we find that: 1) IT exploration capability has a positive effect on IT exploitation capability $(\beta=.71$ and $\mathrm{p}<.01) ; 2)$ IT exploitation capability has a positive effect on customer agility $(\beta=.52$ and $\mathrm{p}<.01)$, operational agility $(\beta=0.47$ and $p<.01)$, and partner agility $(\beta=0.61$ and $p<.01) .3)$; customer agility has a positive effect on market performance $(\beta=0.26$ and $\mathrm{p}<.05)$. 4); operational agility has a positive effect on financial performance $(\beta$ $=0.30$ and $\mathrm{p}<.05)$ and market performance $(\beta=0.20$ and $\mathrm{p}<.10)$; and 5$)$ partner agility has a positive effect on financial performance $(\beta=0.25$ and $\mathrm{p}<.05)$ and market performance $(\beta=0.30$ and $\mathrm{p}<.01)$.

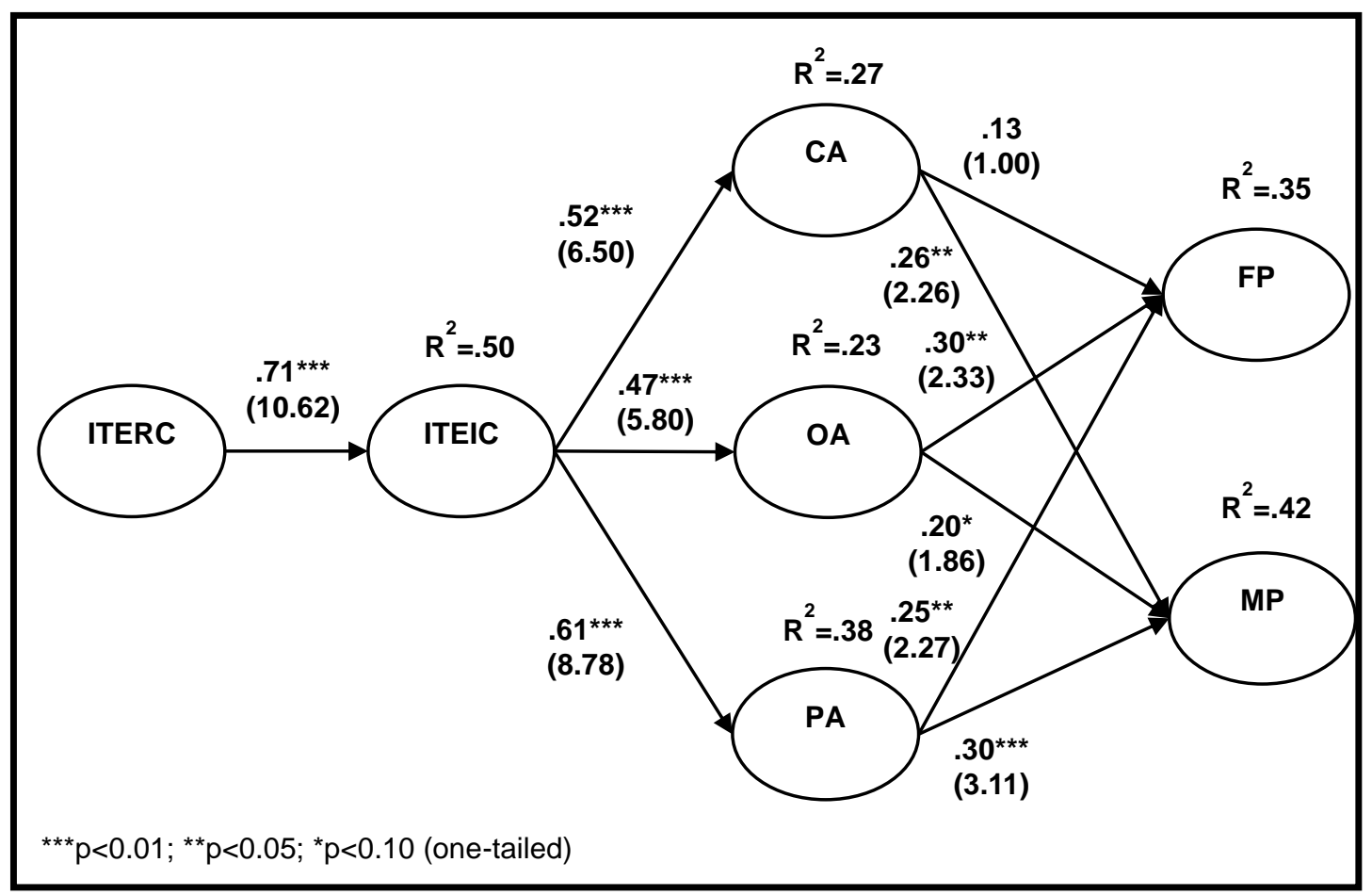

Figure 2. PLS Results

In summary, our results fully support Hypotheses 1, 2a, 2b, 2c, 3b, and 3c. Only hypothesis 3a, the positive effect of customer agility on financial performance, is not supported. 


\section{DISCUSSION}

The enabling role of IT for organizational agility and firm performance observed in this study has several theoretical and managerial implications, which are outlined below.

\subsection{Implications for theory and practice}

Drawing on the resource picking and capability building mechanisms of rent creation, the conceptualization of a hierarchy of capabilities, and the dynamic capability perspective (Grant, 1996; Makadok, 2001; Teece et al., 1997), in this study we attempt to gain a better understanding of how firms can explore and exploit information technologies to enhance their organizational agility. We theoretically delineate the roles of IT in enabling organizational agility at the resource picking stage, which we refer to as IT exploration capability, and at the capability building stage, which we refer to as IT exploitation capability. Our results show that IT exploration capability positively affects IT exploitation capability.

Second, we divide organizational agility into customer, operational, and partner agility (Sambamurthy et al., 2003), which enables us to examine the roles of IT more thoroughly. Our research framework allows for a more precise study of how and where IT enhances organizational agility because these three dimensions cover a firm's entire ecosystem. Subsequently, our findings show that IT exploitation capability positively influences firms' customer, operational, and partner agilities.

Third, our theoretical framework suggests that the three organizational agilities mediate the relationship between IT exploitation capability and performance. Our results confirm this conjecture. Various studies have independently identified the mediating roles of customer, operational, and partner agility on the relationship between IT and firm performance (Inman et al., 2011; Ngai et al., 2011; Roberts \& Grover, 2012; Yusuf \& Adeleye, 2002). However, our study is the first to analyze the combination of all three types of agility. Our findings provide a comprehensive view of how IT influences firm performance. Specifically, it is crucial to first pick the right IT resources, and then convert them into effective IT capabilities. IT capabilities improve firms' abilities to sense and respond to market changes. Finally, IT enabled agility has a positive effect on firm performance.

From a practical perspective, the results of our study have implications for picking the relevant IT resources, converting them into capabilities, and generating organizational change. Specifically, our results show that IT exploitation capability has the largest effect on partner agility, followed by customer agility and operational agility. This suggests that IT provides the most help for firms in terms of improving their abilities to sense and respond to changes in the supply chain. In addition, our results show that of the three types of agility, partner agility has the most pronounced effect on both financial and market performance. This finding is consistent with the idea that IT enabled inter-organizational collaboration is a key factor in creating supply chain agility, and that supply chain agility is one of the core capabilities for creating competitive advantage (Ngai et al., 2011). As a result, to maximize the benefit of investments in IT, managers should focus on the technologies that can enhance supply chain agility when considering different IT options. Investment in IT should aim at developing firm-wide capabilities for efficiently extracting information flows from physical flows and facilitating information sharing with partners for superior demand planning, physical product staging, and business process streamlining. For example, a firm can specifically direct its IT resources to the business analytics of big data to gain a better understanding of the market changes and to coordinate with suppliers to quickly respond to the changes.

\subsection{Limitations and Suggestions for Future Research}

This study has a number of limitations that suggest new avenues for future research. First, our sample is limited to the Pearl River Delta region of China. This region is one of the most vibrant economic centers in China. However, there are no assurances that the IT utilization, understanding, knowhow, and attitudes is this region are similar to those in other areas in China let alone the rest of the world. To extend the applicability of our findings and to better verify our model, future research should use data from other parts of China and perhaps other regions from around the world.

Furthermore, we only focus on manufacturing firms. Future research should use data from a variety of 
sectors, such as banking, services, technology, and transportation. This would enable us to better understand the dynamics of IT resource picking and IT capability building, and their organizational effects.

\section{Conclusion}

In this study, we examine the business value of IT by focusing on the role of IT in enabling organizational agility. Using a research framework based on the well-grounded theoretical perspectives of the resource picking and capability building mechanisms of rent creation, a hierarchy of capabilities, and dynamic capabilities (Grant, 1996; Makadok, 2001; Teece et al., 1997), we examine various enabling factors that enhance organizational agility. In particular, we explore the relationship between IT exploration capability and IT exploitation capability, the effect of IT exploitation capability in enabling organizational agility (customer, operational, and partner), and firm performance. This study offers an important framework for gaining a better understanding of the roles IT plays within organizations from an IT business value perspective in general, and an organizational agility perspective in particular.

We integrate the key variables identified in our research framework into an empirically testable model. By simultaneously testing the relationships between IT exploration capability, IT exploitation capability, customer, operational, and partner agility, and firm performance, we are able to assess the enabling role of IT for organizational agility and performance. Accordingly, our findings provide a number of suggestions for managers with regard to the effective management of IT assets. Our findings suggest that IT resources, when properly managed and directed, can enhance a firm's capabilities in sensing and responding to shifting customer preferences, improving operational efficiency, and better managing the supply chain. Overall, this enhanced agility ultimately has a positive effect on firm performance.

\section{ACKNOWLEDGEMENT}

\section{REFERENCES}

[1] Atuahene-Gima, K. (2005). Resolving the capability: Rigidity paradox in new product innovation. Journal of Marketing, 69(4), 61-83.

[2] Barney, J. B. (1991). Firm resources and sustained competitive advantage. Journal of Management, 17(1), 99-120.

[3] Bharadwaj, A. S. (2000). A resource-based perspective on information technology capability and firm performance: An empirical investigation. MIS Quarterly, 169-196.

[4] Bhatt, G. D., Grover, V., \& Grover, V. (2005). Types of information technology capabilities and their role in competitive advantage: An empirical study. Journal of Management Information Systems, 22(2), 253-277.

[5] Dove, R. (2002). Response ability: the language, structure, and culture of the agile enterprise. John Wiley \& Sons.

[6] Eisenhardt, K. M., \& Martin, J. A. (2000). Dynamic capabilities: What are they? Strategic Management Journal, 21(10-11), 1105-1121.

[7] El Sawy, O. A. (2003). The IS Core IX: The 3 Faces of IS identity: Connection, immersion, and fusion. Communications of the Association for Information Systems, 12(1), 39.

[8] Grant, R. M. (1996). Toward a knowledge-based theory of the firm. Strategic Management Journal, 17, 109-122.

[9] Grover, V., \& Kohli, R. (2012). Cocreating IT value: New capabilities and metrics for multifirm environments. MIS Quarterly, 36(1), 225-232.

[10] Inman, R. A., Sale, R. S., Green, K.W., \& Whitten, D. (2011). Agile manufacturing: Relation to JIT, operational performance and firm performance. Journal of Operations Management, 29(4), 343-355

[11] Johns, G. (2006). The essential impact of context on organizational behavior. Academy of Management Review, 31(2), 386-408.

[12] Karimi, J., Somers, T. M., \& Bhattacherjee, A. (2007). The role of information systems resources in ERP capability building and business process outcomes. Journal of Management Information Systems, 24(2), 221-260.

[13] Kassim, N. M., \& Zain, M. (2004). Assessing the measurement of organizational agility. Journal of American 
Academy of Business, Cambridge, 4(1), 2.

[14] Lee, O.-K. D., Sambamurthy, V., Lim, K., \& Wei, K. (2008). IT-enabled organizational agility and sustainable competitive advantage. Vallabh, Lim, Kai and Wei, KK, IT-Enabled Organizational Agility and Sustainable Competitive Advantage (August 23, 2008).

[15] Lee, O.-K. D., Xu, P., Kuilboer, J.-P., \& Ashrafi, N. (2012). IT impacts on performance of service firms through operation-level dynamic capability. Journal of Applied Business Research (JABR), 28(6), 1283-1294.

[16] Makadok, R. (2001). Toward a synthesis of the resource - based and dynamic - capability views of rent creation. Strategic Management Journal, 22(5), 387-401.

[17] Maritan, C. A., \& Peteraf, M. A. (2011). Invited editorial: Building a bridge between resource acquisition and resource accumulation. Journal of Management, 37(5), 1374-1389.

[18] Mathiassen, L., \& Pries-Heje, J. (2006). Business agility and diffusion of information technology. European Journal of Information Systems, 15(2), 116-119.

[19] Mithas, S., Ramasubbu, N., \& Sambamurthy, V. (2011). How information management capability influences firm performance. MIS Quarterly, 35(1), 237-256.

[20] Nambisan, S., Agarwal, R., \& Tanniru, M. (1999). Organizational mechanisms for enhancing user innovation in information technology. MIS Quarterly, 23(3), 365-395.

[21] Ngai, E. W., Chau, D. C., \& Chan, T. L. A. (2011). Information technology, operational, and management competencies for supply chain agility: Findings from case studies. Journal of Strategic Information Systems, 20(3), 232-249.

[22] Overby, E., Bharadwaj, A., \& Sambamurthy, V. (2006). Enterprise agility and the enabling role of information technology. European Journal of Information Systems, 15(2), 120-131.

[23] Pavlou, P., \& El Sawy, O. (2010). The third hand: IT-enabled competitive advantage in turbulent environments. Information Systems Research, 21(3), 443-471.

[24] Pavlou, P. A., \& El Sawy, O. A. (2006). From IT leveraging competence to competitive advantage in turbulent environments: The case of new product development. Information Systems Research, 17(3), 198-227.

[25] Peppard, J., \& Ward, J. (2004). Beyond strategic information systems: Towards an IS capability. Journal of Strategic Information Systems, 13(2), 167-194.

[26] Ravichandran, T., Lertwongsatien, C., \& Lertwongsatien, C. (2005). Effect of information systems resources and capabilities on firm performance: A resource-based perspective. Journal of Management Information Systems, 21(4), 237-276.

[27] Ringle, C. M., Wende, S., \& Will, S. (2005). SmartPLS 2.0 (M3) Beta, Hamburg. Available from http://www. smartpls. de.

[28] Roberts, N., \& Grover, V. (2012). Investigating firm's customer agility and firm performance: The importance of aligning sense and respond capabilities. Journal of Business Research, 65(5), 579-585.

[29] Sambamurthy, V., Bharadwaj, A., \& Grover, V. (2003). Shaping agility through digital options: Reconceptualizing the role of information technology in contemporary firms. MIS Quarterly, 27(2). 237-263.

[30] Santhanam, R., \& Hartono, E. (2003). Issues in linking information technology capability to firm performance. MIS Quarterly, 125-153.

[31] Seo, D., \& La Paz, A. I. (2008). Exploring the dark side of IS in achieving organizational agility. Communications of the ACM, 51(11), 136-139.

[32] Sharifi, H., \& Zhang, Z. (2001). Agile manufacturing in practice: Application of a methodology. International Journal of Operations \& Production Management, 21(5/6), 772-794.

[33] Tallon, P. P. (2008). Inside the adaptive enterprise: An information technology capabilities perspective on business process agility. Information Technology and Management, 9(1), 21-36.

[34] Tallon, P.P. \& Pinsonneault, A. (2011). Competing perspectives on the link between strategic information technology alignment and organizational agility: Insights from a mediation model. MIS Quarterly, 35(2), 463-486.

[35] Teece, D. J., Pisano, G., \& Shuen, A. (1997). Dynamic capabilities and strategic management. Strategic Management Journal, 18(7), 509-533.

[36] Yusuf, Y.Y. \& Adeleye, E.O. (2002). A comparative study of lean and agile manufacturing with a related survey of current practices in the UK. International Journal of Production Research, 40(17), 4545-4562. 